\title{
A Residência Pedagógica na licenciatura em Ciências Biológicas no contexto da pandemia: um relato de experiência
}

The Pedagogical Residence in the Biological Sciences degree in the context of the pandemic: an experience report

La Residencia Pedagógica en la carrera de Ciencias Biológicas en el contexto de la pandemia: un relato de experiência

Diogo Leonardo Santos Silva ORCID: https://orcid.org/0000-0003-0718-831X Universidade Federal de Campina Grande, Brasil E-mail: diogoleonardosantossilva@yahoo.com

Mayara Islaine Pessoa de Souza ORCID: https://orcid.org/0000-0001-8011-163X Universidade Federal de Campina Grande, Brasil E-mail: mayaraislainne@gmail.com

Inácio Ferreira da Silva Júnior ORCID: https://orcid.org/0000-0001-9732-5343 Universidade Federal de Campina Grande, Brasil E-mail: inaciofjunior@hotmail.com Suzy Nunes Crispim ORCID: https://orcid.org/0000-0003-4941-9198 Escola Estadual Cidadã Integral Orlando Venâncio dos Santos, Brasil E-mail: suzybio22@gmail.com

Lilian Arruda Ribeiro ORCID: https://orcid.org/0000-0003-0655-2925 Universidade Federal de Campina Grande, Brasil E-mail: lilianarruda@gmail.com

Márcio Frazão Chaves ORCID: https://orcid.org/0000-0002-0341-2882 Universidade Federal de Campina Grande, Brasil E-mail: marciochavesufcg@gmail.com

\begin{abstract}
Resumo
A pandemia da COVID-19 foi provocada pela rápida disseminação mundial do seu agente etiológico, o SARS-CoV-2. O contexto de crise sanitária provocou alterações na funcionalidade de diversos setores da sociedade, incluído a educação. Nesta perspectiva, para atenuar os danos da pandemia no processo de ensino-aprendizagem, muitas instituições adotaram o ensino remoto emergencial. Contudo, a carência de acesso à tecnologia, bem como os distúrbios psicológicos provocados pela pandemia, estão associados com deficiências no aprendizado de vários estudantes. Além disso, os docentes e os alunos da Residência Pedagógica se depararam com a necessidade de adaptar sua metodologia ao ensino remoto. Deste modo, foi objetivo descrever as experiências observadas e obtidas por alunos da Residência Pedagógica, do curso de Ciências Biológicas, da Universidade Federal de Campina Grande, durante a vigência do programa em uma escola pública do município de Cuité - Paraíba - Brasil. Os residentes, sob a supervisão da docente preceptora, participaram de atividades acadêmicas como a elaboração e a execução de aulas, momentos de discussão e correção de atividades sobre os temas abordados nas aulas remotas. Nesta perspectiva, é evidente que mesmo com a execução da vigência da Residência Pedagógica no ensino remoto, este programa proporcionou a obtenção de experiências profissionais relevantes para a prática docente. Além disso, julga-se necessária a manutenção das ofertas de vagas e bolsas deste programa nas instituições de ensino superior, uma vez que contribui significativamente para melhorar a qualidade profissional de docentes em formação.
\end{abstract}

Palavras-chave: Ensino remoto; COVID-19; Formação de docentes.

\section{Abstract}

The COVID-19 pandemic was caused by the rapid worldwide spread of its etiological agent, SARS-CoV-2. The context of the health crisis caused changes in the functionality of various sectors of society, including education. In this perspective, to mitigate the damages of the pandemic in the teaching-learning process, many institutions have adopted emergency remote teaching. However, the lack of access to technology, as well as the psychological disorders 
caused by the pandemic, are associated with deficiencies in the learning of many students. In addition, teachers and students of the Pedagogical Residence faced the need to adapt their methodology to remote teaching. Thus, the objective was to describe the experiences observed and obtained by students of the Pedagogical Residence, of the Biological Sciences course, at the Federal University of Campina Grande, during the duration of the program in a public school in the city of Cuité - Paraíba - Brazil. The residents, under the supervision of the preceptor teacher, participated in academic activities such as the preparation and execution of classes, moments of discussion and correction of activities on the topics covered in remote classes. In this perspective, it is evident that even with the implementation of the Pedagogical Residency in remote teaching, this program provided the attainment of relevant professional experiences for the teaching practice. In addition, it is deemed necessary to maintain the offers of vacancies and scholarships for this program in higher education institutions, since it significantly contributes to improving the professional quality of teachers in training.

Keywords: Remote teaching; Pandemic; Teacher training.

\section{Resumen}

La pandemia de COVID-19 fue causada por la rápida propagación mundial de su agente etiológico, el SARS-CoV-2. El contexto de la crisis sanitaria provocó cambios en la funcionalidad de varios sectores de la sociedad, incluido el educativo. En esta perspectiva, para mitigar los daños de la pandemia en el proceso de enseñanza-aprendizaje, muchas instituciones han adoptado la enseñanza a distancia de emergencia. Sin embargo, la falta de acceso a la tecnología, así como los trastornos psicológicos provocados por la pandemia, están asociados a deficiencias en el aprendizaje de muchos estudiantes. Además, docentes y estudiantes de la Residencia Pedagógica se enfrentaron a la necesidad de adaptar su metodología a la enseñanza a distancia. Así, el objetivo fue describir las experiencias observadas y obtenidas por estudiantes de la Residencia Pedagógica, del curso de Ciencias Biológicas, en la Universidad Federal de Campina Grande, durante la duración del programa en una escuela pública en la ciudad de Cuité - Paraíba - Brasil. Los residentes, bajo la supervisión del maestro preceptor, participaron de actividades académicas como la preparación y ejecución de clases, momentos de discusión y corrección de actividades sobre los temas tratados en las clases a distancia. En esa perspectiva, se evidencia que aun con la implementación de la Residencia Pedagógica en la enseñanza a distancia, este programa permitió la consecución de experiencias profesionales relevantes para la práctica docente. Además, se considera necesario mantener las ofertas de vacantes y becas de este programa en las instituciones de educación superior, ya que contribuye significativamente a mejorar la calidad profesional de los docentes en formación.

Palabras clave: Enseñanza remota; COVID-19; Formación de profesores.

\section{Introdução}

A doença do coronavírus 2019 (COVID-19) trata-se de uma doença infeciosa provocada pelo SARS-CoV-2 (coronavírus da síndrome respiratória aguda grave 2) (SILVA et al., 2021). O agente etiológico da COVID-19 foi inicialmente identificado em Wahan, na China, em 31 de dezembro de 2020 (Lana et al., 2020). Em 30 de janeiro de 2020, a Organização Mundial da Saúde designou a COVID-19 como um grave problema de saúde pública com relevância a nível mundial (Oliveira et al., 2020). Posteriormente, a disseminação do vírus pelos continentes fez com que a COVID-19 atingisse a magnitude de pandemia, sendo a esta atribuída tal categoria no dia 11 de março de 2020 (Silva et al., 2021).

A COVID-19 pode ser transmitida através do contato direto com pessoas ou superfícies contaminadas com o agente etiológico, bem como por gotículas expelidas por um indivíduo infectado. Geralmente, a infecção ocorre por contato numa distância de menos de um metro (Brasil, 2021). Além disso, sabe-se que, quanto mais o vírus infectar pessoas, maiores são as chances de mutação neste microrganismo. Nesta perspectiva, uma das estratégias mais eficazes adotada para atenuar a disseminação viral é reduzir os riscos de exposição (OMS, s.d).

A crise sanitária desencadeada pela COVID-19 provocou danos graves em vários setores da sociedade, como a economia, a saúde, e a educação, tendo em vista a carência de preparo e planejamento para melhor condução de tais atividades durante este período (Andrade Costa et al., 2021). Contudo, esta deficiência pode está relacionada com o fato do atual cenário de pandemia ser uma crise sanitária inédita, onde os saberes sobre o tema ainda encontram-se em construção (Pontes et al., 2021).

Para atenuar os danos que a pandemia da COVID-19 na educação, várias instituições de ensino como universidades e escolas optaram por migrar para o ensino online, realizado através de plataformas digitais. No cenário nacional, os governantes 
implantaram o ensino remoto (ER) com caráter emergencial e temporário como estratégia para a retomada das aulas, diferindose do ensino à distância (Nakano et al., 2021).

O ER possui a finalidade de promoção da continuidade da educação durante o atual período de crise sanitária, de modo mais rápido e seguro. É uma estratégia de ensino temporária, uma vez que, as modalidades de ensino híbrido ou presencial retornarão à funcionalidade quando houver atenuação ou fim da pandemia da COVID-19 (Hodges et al., 2020).

No que tange aos impactos do ER, é evidente a intensificação das condições socioeconômicas, tendo em vista que nem todos os alunos possuem recursos necessários e de qualidade para o acesso à educação, bem como a dificuldade de aprendizagem imposta por problemas psicoemocionais desencadeados pelo contexto pandêmico (Andrade Costa et al., 2021).

O Programa Institucional de Residência Pedagógica (RP) trata-se de um programa acadêmico exclusivo para alunos de licenciaturas, sendo as vagas ofertadas para estudantes que tenham concluído ao menos metade do curso. O objetivo de tal programa é proporcionar aos participantes as experiências profissionais em sala de aula da educação básica (Capes, 2020), contribuindo para o aperfeiçoamento de competências e habilidades didáticas e metodológicas (Felipe \& Bahia, 2020). Embora realizado geralmente de forma presencial, a influência da pandemia migrou a vigência do programa para o espaço virtual, onde os residentes tiveram que se adequar ao novo modelo de ensino, assim como ocorreu no estudo de Santos (2021).

As experiências proporcionadas pela RP são essenciais para a junção da teoria com a prática. Além disso, as vivências no ambiente de ensino contribuem para reestruturação, conquistas e descobertas do profissional docente, bem como ocorre à percepção da complexidade e dos obstáculos encontrados durante o processo de ensino, resultando na busca por melhorias neste cenário (Maciel et al., 2020).

Diante do que foi relatado na literatura científica, foi objetivo descrever as experiências proporcionadas através do Programa Institucional de RP, da Universidade Federal de Campina Grande (UFCG)/ Centro de Educação e Saúde (CES), no curso de licenciatura em Ciências Biológicas, durante o quarto bimestre do ano letivo de 2021, em uma escola pública de ensino médio, em um município da Paraíba - Brasil.

\section{Metodologia}

Trata-se de um estudo do tipo relato de experiência, realizado a partir da descrição de atividades pedagógicas observadas e conduzidas durante a vigência de um período do Programa Institucional de RP, em uma escola estadual localizada no município de Cuité - Paraíba - Brasil.

O relato de experiência consiste em uma das formas de produção do conhecimento científico, construído a partir da descrição de experiências profissionais e/ou acadêmicas vivenciadas nos cenários do ensino, pesquisa ou extensão. Além disso, a principal característica desta modalidade de estudo científico é a descrição de uma intervenção (Mussi et al., 2021).

Para a construção deste relato de experiência foram adotadas algumas etapas norteadoras sugeridas por Mussi et al., (2021), a fim de garantir a relevância científica do estudo. Estas etapas encontram-se abaixo na Tabela 1. 
Tabela 1. Etapas adotadas para o relato de experiência.

\begin{tabular}{c|c}
\hline Seção & Elementos norteadores \\
\hline Introdução & $\begin{array}{c}\text { Conceitos chaves sobre a temática; } \\
\text { Relevância sobre a temática; } \\
\text { Objetivo. }\end{array}$ \\
\hline Metodologia & $\begin{array}{c}\text { Descrição do período temporal e do local de realização. } \\
\text { Descrição das atividades realizada. }\end{array}$ \\
\hline Resultados & Experiências observadas/obtidas. \\
\hline Discussão & $\begin{array}{c}\text { Diálogo com a literatura científica; } \\
\text { Reflexão crítica. }\end{array}$ \\
\hline Considerações Finais & Verificação do cumprimento do intuito do relato. \\
\hline Referências & Material científico utilizado para embasamento do relato. \\
\hline
\end{tabular}

Fonte: Mussi et al., (2021).

A vigência do programa de RP ocorreu no período de outubro a dezembro de 2021, na Escola Estadual Cidadã Integral Orlando Venâncio dos Santos, onde são ofertadas apenas turmas de ensino médio. Nesta instituição, até o período de vigência da RP, encontravam-se matriculados 409 alunos. Para atender a demanda do ensino médio, a escola dispunha de 22 professores.

Os residentes do programa tiveram a oportunidade de imersão à docência a partir do contato com quatro turmas: $1^{\circ}$ ano $\mathrm{A}, 2^{\circ}$ ano $\mathrm{A}, 3^{\circ}$ ano $\mathrm{B}$ e $\mathrm{C}$. No total, aproximadamente 50 alunos destas turmas participaram dos encontros síncronos no ER, sendo 10 alunos do $1^{\circ}$ ano, 10 do $2^{\circ}$ ano, e 30 de ambos os $3^{\circ}$ anos.

No que tange à modalidade de ensino da instituição onde foi conduzida a vigência do programa de RP, esta ofertou o ensino híbrido, onde foram administradas três aulas por semana através da plataforma virtual Google Meet, e apenas uma aula presencial semanal, seguindo as diretrizes do plano de contingenciamento contra a COVID-19 na escola. A fim de minimizar os riscos de contaminação pela COVID-19, optou-se por executar a vigência da RP através do ER.

\section{Resultados}

Com o programa de RP, os residentes tiveram a oportunidade de realizar e observar diversas atividades acadêmicas ao longo do bimestre. As principais atividades de classe realizadas encontram-se descritas abaixo na Tabela 2.

Tabela 2. Descrição das atividades de classe realizadas na RP ao longo do bimestre.

\begin{tabular}{|c|c|c|}
\hline Turmas & Conteúdos ministrados & Atividades realizadas na RP \\
\hline $1^{\circ}$ ano $\mathrm{A}$ & $\begin{array}{l}\text { Divisão Celular; } \\
\text { Reprodução; } \\
\text { Desenvolvimento; } \\
\text { Histologia. } \\
\end{array}$ & $\begin{array}{c}\text { Planejamento e elaboração de aulas expositivas e } \\
\text { dialogadas; } \\
\text { Discussões com os alunos sobre os conteúdos } \\
\text { minsitrados. }\end{array}$ \\
\hline $2^{\circ}$ ano $\mathrm{A}$ & $\begin{array}{l}\text { Filo Porifera; } \\
\text { Filo Cnidaria; } \\
\text { Filo Platyhelminthes; } \\
\text { Filo Nematoda; } \\
\text { Filo Mollusca; } \\
\text { Filo Annelida. }\end{array}$ & $\begin{array}{l}\text { Planejamento e elaboração de aulas expositivas e } \\
\text { dialogadas; } \\
\text { Resolução de questões acerca dos conteúdos } \\
\text { ministrados. }\end{array}$ \\
\hline $3^{\circ}$ ano $\mathrm{B} / \mathrm{C}$ & $\begin{array}{l}\text { Conceitos básicos em genética; } \\
\text { Primeira Lei de Mendel; } \\
\text { Segunda Lei de Mendel; } \\
\text { Heredograma. }\end{array}$ & $\begin{array}{l}\text { Planejamento e elaboração de aulas expositivas e } \\
\text { dialogadas; } \\
\text { Resolução de questões acerca dos conteúdos } \\
\text { ministrados. }\end{array}$ \\
\hline
\end{tabular}

Fonte: Autores. 
$\mathrm{Na}$ turma do primeiro ano do ensino médio, os residentes tiveram a oportunidade de realizar o planejamento e a execução de aulas teóricas, bem como de promover discussões com os alunos sobre os conteúdos do quarto bimestre. As discussões foram conduzidas por meio de curiosidades relacionadas aos temas das aulas ministradas pelos residentes.

Nas turmas do segundo e terceiro ano do ensino médio também foram realizados o planejamento e a execução de aulas expositivas dialogadas sobre os conteúdos do bimestre em questão. Além disso, nestas turmas, também foram realizadas resoluções de questões a cerca dos temas trabalhados.

Nos três níveis do ensino médio, todo o planejamento e execução de aulas foram supervisionados pela professora preceptora da disciplina, garantindo a identificação de possíveis pontos a serem melhorados, bem como sugestões de melhorias para estes.

No tocante ao relacionamento das turmas para com os residentes e vice-versa, o contato entre estes ocorreu através do uso do microfone ou do chat disponível pela plataforma Google Meet, sendo essenciais para a discussão dos temas, retiradas de dúvidas e questionamentos, bem como para a correção das questões sobre os temas trabalhados. Além disso, observou-se que, um número considerado de alunos presentes nas aulas remotas esteve disposto a serem participativos nos encontros síncronos.

No que tange ao material didático utilizado nas aulas síncronas (slides das aulas e os questionários sobre os conteúdos), este foi disponibilizado após a conclusão de cada temática trabalhada para os discentes, através da plataforma Google Classroom, a fim de cativar os alunos a manterem a rotina de estudos, mesmo com as dificuldades e limitações impostas pelo ER.

A RP também possibilitou os residentes a observarem e analisarem as metodologias, o domínio e a didática para lecionar os conteúdos, bem como a conduta adotada pela docente preceptora, servindo como modelo inspirador aos residentes durante a vigência do programa no bimestre.

Os residentes também participaram de atividades extraclasses, como por exemplo, participação como ouvinte de reuniões do planejamento escolar, e contato com a gestão da escola, mesmo que de modo limitado.

Por fim, a necessidade de adaptação e adequação das metodologias do ensino presencial ao ER despertou nos residentes habilidades e competências para buscar estratégias para o ensino, identificar seus pontos positivos e negativos, proporcionando experiências únicas que possam ser necessárias para melhor compreensão do processo de ensinoaprendizagem, possibilitando uma maior autonomia, segurança e capacitação profissional. Além disso, julga-se que, tais vivências podem contribuir para uma melhor maturidade para o enfrentamento de futuros cenários de crises sanitárias e seus impactos na educação.

\section{Discussão}

O Programa Institucional de RP pode ser considerado um momento de transição para o discente da licenciatura e o profissional docente. A oferta de tal programa torna-se essencial, tendo em vista que o docente em formação necessita desenvolver habilidades para identificar obstáculos e propor soluções que possivelmente estarão presentes no cotidiano do profissional docente (Alves et al., 2021).

A implantação do programa de RP possibilitou o aperfeiçoamento da formação de docentes, ampliando seus horizontes. Tal fato vem contribuindo para a melhoria do ensino no Brasil (Mello et al., 2020). No estudo realizado por Freitas et al. (2020) foi relatado que a RP promoveu troca de saberes entre a universidade e a escola, contribuindo para aprimorar a formação acadêmica do residente, sobretudo proporcionando o conhecimento do atual cenário do ensino público.

No tocante a RP durante o ER, Pereira (2021) relatou em seu estudo a execução da vigência neste período foi mais agregador do que o ensino presencial convencional, devido à necessidade de criar novas práticas e possibilidades para a iniciação à docência. Paula et al. (2021) enalteceram a partir do seu relato que a RP no ER promoveu além de maior adaptação 
dos residentes as necessidades da educação, também a observação das dificuldades enfrentadas por vários docentes na nova modalidade de ensino, no atual contexto pandêmico.

Gnoatto et al. (2021) perceberam a partir das experiências adquiridas com a RP, durante a vigência online, que este programa acadêmico possibilita estudos, reflexões, experiências pessoais e profissionais sobre diversos conteúdos. Além disso, os autores relataram que as vivências do programa são fundamentais para a formação profissional, uma vez que permite a aplicação dos conhecimentos dos residentes à prática docente.

Sousa e Barroso (2019) relataram que a RP possibilitou o desenvolvimento da análise crítica sobre o contexto do ensino no qual a residente participou através do programa, por meio da imersão na docência antes da inserção no mercado de trabalho. Além disso, as autoras afirmaram que a participação das atividades de classe e extraclasse no ambiente escolar possibilitou melhor compreensão do funcionamento da instituição de ensino.

É evidente que a literatura científica apresenta diversos pontos positivos a favor da importância do programa de RP na formação docente dos alunos das licenciaturas. Vários destes pontos foram observados durante a vigência da RP no quarto bimestre da escola contemplada pelo programa, assim como relatado neste estudo. Isto corrobora para evidenciar a necessidade, importância e retorno para a sociedade que a RP desempenha na formação profissional dos alunos de licenciatura.

\section{Considerações Finais}

Mesmo com as limitações impostas pelo atual cenário pandêmico sobre o sistema de ensino brasileiro e de formação de docentes, nota-se que o Programa Institucional de RP foi capaz de proporcionar experiências fundamentais na formação de docentes. Nesta perspectiva, nota-se que este programa acadêmico possui grande relevância para a formação docente em Ciências Biológicas, bem como das demais licenciaturas. Nesta perspectiva, a manutenção da oferta de vagas e bolsas na RP pelas instituições de ensino superior pode contribuir para melhorar a qualidade profissional do acadêmico em licenciatura.

Com base nas experiências vivenciadas com a RP durante a vigência no ensino remoto, julga-se essencial que os pesquisadores na área relatem suas experiências obtidas por meio do programa para fomentar a relevância da RP no processo de ensino-aprendizagem e de formação de docentes, contribuindo para o enriquecimento da literatura científica sobre esta temática, e solidificação da oferta de vagas e bolsas deste programa institucional para alunos das licenciaturas.

\section{Agradecimentos}

Os autores agradecem à Coordenação de Aperfeiçoamento de Pessoal de Nível Superior - CAPES pela concessão das bolsas, bem como pelas oportunidades e experiência proporcionadas pelo programa, durante o período de vigência.

\section{Referências}

Alves, F. E. H. de M. Ferreira, A. P., Santos, A. R. dos, \& Bezerra M. R. O. S. (2021). Relato de experiência no programa residência pedagogica: vivências e desafios no ensino remoto. Anais do III Congresso Internacional e V Congresso Nacional de Movimentos Sociais e Educação.

Andrade Costa, J. de, Machado, D. de C. P., Andrade Costa, T. de, Araújo, F. da. C., Nunes, J. C., \& Costa, H. T. S. da. (2021). Dificuldades enfrentadas durante o ensino remoto. Revista Brasileira de Ensino e Aprendizagem, 1, 80-95.

Brasil. Ministério da Saúde. (2021, 12 de maio). Coronavírus: como é transmitido? https://www.gov.br/saude/pt-br/coronavirus/como-e-transmitido.

Capes (Coordenação de Aperfeiçoamento de Pessoal de Nível Superior). (2020, 15 de setembro). Programa de Residência Pedagógica. Disponível em: https://www.gov.br/capes/pt-br/acesso-a-informacao/acoes-e-programas/educacao-basica/programa-residencia-pedagogica.

Felipe, E. da S., \& Bahia, C. da C. S. (2020). Aprendendo a ser professor: as contribuições do programa Residência Pedagógica. Formação Docente, 12(25), 81-94, 2020. https://doi.org/10.31639/rbpfp.v13i25.436.

Freitas, M. C. de, Freitas, B. M. de, \& Almeida, D. M. (2020) Residência pedagógica e sua contribuição na formação docente. Ensino em Perspectivas, 1(2), $1-12$. 
Gnoatto, E. S., Brock, G. M. C., \& Wirzbicki, S. M. (2021). Uma reflexão sobre o ensino on-line num programa de residência pedagógica. Encontro sobre Investigação na Escola, 17(1), 1-5.

Hodges, C., Trust, T., Moore, S., Bond, A., \& Lockee, B. (2020). As diferenças entre o aprendizado online e o ensino remoto de emergência. Revista da escola, professor, educação e tecnologia, 2.

Lana, R. M., Coelho, F. C., Costa Gomes, M. F. da, Cruz, O. G., Bastos, L. S., Villela, D. A. M., \& Codeço, C. T. (2020). Emergência do novo coronavírus (SARS-CoV-2) e o papel de uma vigilância nacional em saúde oportuna e efetiva. Cadernos de Saúde Pública, 36(3), e00019620. https://doi.org/10.1590/0102-311X00019620.

Maciel, A. de O., Lima Nunes, A. I. B., \& Pontes Junior, J. A. de F. (2020). Estágio Supervisionado e Residência Pedagógica: possibilidades para formação docente crítica. Revista Ibero-Americana de Estudos em Educação, 15, 2223-2239. https://doi.org/10.21723/riaee.v15iesp3.14428.

Mello, D. E. de, Moraes, D. A. F. de, Franco, S. A. P., Assis, E. F. de, \& Potoski, G. (2020). O programa residência pedagógica-experiências formativas no curso de pedagogia. Revista Online de Política e Gestão Educacional, 24(2), 518-535. https://doi.org/10.22633/rpge.v24i2.13631.

Mussi, R. F. de F., Flores, F. F., \& Almeida C. B. de. (2021). Pressupostos para a elaboração de relato de experiência como conhecimento científico. Revista Práxis Educacional, 17(48), 60-77. https://doi.org/10.22481/praxisedu.v17i48.9010.

Nakano, T. de C., Roza, R. H., \& Oliveira, A. W. de. (2021). Ensino remoto em tempos de pandemia: reflexões sobre seus impactos. e-Curriculum, 19(3), 1368-1392. https://doi.org/10.23925/1809-3876.2021v19i3p1368-1392.

Oliveira, W. K. de, Duarte, E., França, G. V. A. de, Garcia, L. P. (2020). Como o Brasil pode deter a COVID-19. Epidemiologia e Serviços de Saúde, 29(2), e2020044. http://dx.doi.org/10.5123/s1679-49742020000200023.

OMS (Organização Mundial da Saúde). (s.d.). Folha informativa sobre COVID-19. https://www.paho.org/pt/covid19.

Paula, G. S. N. de, Souza, S. B., Salgado, S. C. M., \& Faria, D. Y. de. (2021). A residência pedagógica e a pandemia: implicações do ensino remoto. Anais Educação em Foco: IFSULDEMINAS, 1(1).

Pereira, C. M. (2021) O programa residência pedagógica no núcleo da matemática dentro contexto do ensino remoto. 2021. Trabalho de Conclusão de Curso (Licenciatura em Matemática), Universidade Federal do Pampa, Bagé, Brasil 2021.

Pontes, J. L., Cardoso, A. C., Santos, D. C. dos, Oliveira, P. R. de, Lemos, A. R. P. de, Oliveira Neto, A. V. de, \& Coelho Neto, G. C. (2021). Oferta assistencial de leitos de referência à covid-19 nas regiões de saúde de Pernambuco. Revista de Administração em Saúde (online), $21(83)$, e292. http://dx.doi.org/10.23973/ras.83.292.

Santos, A. G. F. (2021). Relato de experiência no programa residência pedagógica durante o ensino remoto. Gênero e Interdisciplinaridade, 2(5).

Silva, D. L. S., Gomes Rafael, K. J., Freires da Silva, J. E. C., Silva, A. A. S., Lima Monteiro, M. H. de, Silva, S. M. B. da, Silva, L. de O., \& Vilar de Miranda, L. S. M. (2021). Avaliação da mortalidade por COVID-19 no Brasil. Brazilian Journal of Health Review, 4(4), 14756-14766. http://dx.doi.org/10.34119/bjhrv4n4-033.

Sousa, D. A. de, \& Barroso, M. L. (2019). A formação inicial docente em Educação Física a partir do Programa Residência Pedagógica: um relato de experiência. Práticas Educativas, Memórias e Oralidades, 1(2), 1-15. http://dx.doi.org/10.47149/pemo.v1i2.3570. 